\title{
Salivary Gland Homogenates of Lutzomyia longipalpis and Its Vasodilatory Peptide Maxadilan Cause Plasma Leakage via PAC1 Receptor Activation
}

\author{
Erik Svensjö $^{a} \quad$ Elvira M. Saraivab ${ }^{b}$ Marcelo T. Bozzab Sandra M.P. Oliveirac \\ Ethan A. Lerner ${ }^{d}$ Julio Scharfstein ${ }^{a}$ \\ Institutos de a Biofísica Carlos Chagas Filho e de ${ }^{b}$ Microbiologia Prof. Paulo de Goes, Universidade Federal do \\ Rio de Janeiro, e 'Fundação Oswaldo Cruz, Rio de Janeiro, Brasil; ${ }^{\mathrm{d} C}$ Cutaneous Biology Research Center, \\ Boston, Mass., USA
}

\section{Key Words}

Arteriolar dilation • Lutzomyia longipalpis • Maxadilan •

PAC1 receptor $\cdot$ Pituitary adenylate cyclase-activating

peptide Plasma leakage • Postcapillary venules •

Salivary glands

\begin{abstract}
Objectives: Experiments were designed to determine if salivary gland homogenates (SGH) of the sand fly Lutzomyia longipalpis, the vasodilatory peptides maxadilan and pituitary adenylate cyclase-activating peptide (PACAP-38) may cause plasma leakage and to what extent these effects could be due to PAC1 receptor stimulation. Methods: Using FITCdextran as a plasma marker, intravital microscopy of the hamster cheek pouch (HCP) and a digital camera were used to assess arteriolar diameter and fluorescence of a selected area $\left(5 \mathrm{~mm}^{2}\right)$ representative of the HCP microcirculation. Results: Cheek pouches prepared for intravital microscopy and exposed to topical application of SGH, maxadilan or PACAP-38 developed maximal dilation of arterioles in the range of 20 $60 \mu \mathrm{m}$ within $10 \mathrm{~min}$, and this effect lasted for 30-90 min. The increase in fluorescence intensity induced by each of these compounds was due to plasma leakage from postcapillary venules. The mutant peptide of maxadilan (M-65), a PAC1 re-
\end{abstract}

ceptor antagonist, inhibited both dilation and plasma leakage induced by SGH or maxadilan. Plasma leakage induced by SGH was modestly inhibited by the bradykinin $\mathrm{B}_{2}$ receptor antagonist HOE-140, but not by the antihistamine mepyramine or the nitric oxide synthase inhibitor L-NA. Conclusions: SGH of L. longipalpis and its vasodilatory peptide maxadilan caused long-lasting arteriolar dilation and plasma leakage in the cheek pouch via PAC1 receptor activation.

Copyright $\odot 2009$ S. Karger AG, Basel

\section{Introduction}

Saliva of blood-feeding arthropods plays an important role in food ingestion as well as pathogen transmission. Saliva injected into vertebrate hosts contains active molecules that not only counteract vertebrate hemostasis, allowing the arthropods to feed successfully [1], but also modulate host immune responses [2]. Among these arthropods, phlebotomine sand flies are the vectors of Leishmania parasites, the causal agents of leishmaniasis, a disease affecting 2 million people annually in 88 countries [3]. Lutzomyia longipalpis, the New World vector of Leishmania chagasi, is the main vector of the visceral form of leishmaniasis, being fatal if untreated [4]. Leish-

\section{KARGER}

Fax +41613061234 E-Mail karger@karger.ch www.karger.com
(C) 2009 S. Karger AG, Basel

$1018-1172 / 09 / 0465-0435 \$ 26.00 / 0$

Accessible online at:

www.karger.com/jvr
Dr. Erik Svensjö

Laboratório de Imunologia Molecular, Instituto Biofísica Carlos Chagas Filho

Universidade Federal do Rio de Janeiro, CCS-Cidade Universitária

21944-900 Rio de Janeiro (Brazil)

Tel. +55 2209 6591, Fax +55 212280 8193, E-Mail erik.svensjo@gmail.com 
mania are transmitted when female sand flies salivate in the biting site while obtaining their blood meal. Saliva, which contains a vast array of pharmacologically active substances allowing blood feeding, may also enhance or facilitate infectivity of parasites by downmodulating host immune responses [5-7]. Several studies have shown that salivary gland lysates, or its most active vasodilator component, maxadilan, may enhance infectivity of $L$. chagasi, L. donovani, L. major, L. braziliensis and L. amazonensis [8-12]. Among the repertoire of L. longipalpis salivary proteins, the potent vasodilator named maxadilan was characterized and cloned [13-15]. Cloning of the maxadilan gene revealed that the primary sequence of this polypeptide has no homology to that of pituitary adenylate cyclase-activating peptide (PACAP), despite the fact that maxadilan is an agonist of the $\mathrm{PAC1}$ receptor, one of the three receptors of PACAP $[16,17]$. PACAP is a member of the secretin/glucagon/vasoactive intestinal peptide superfamily of peptides, originally isolated from the ovine brain in 1989 [18]. Two biologically active forms, PACAP-38 and PACAP-27, have been derived from proteolytic processing of a single 176 -amino acid precursor $[19,20]$. More recently, Reddy et al. [21] engineered several mutants of the 61-amino acid vasodilator peptide maxadilan and then proceeded to characterize their binding specificity for the PAC1 receptor. Based on this analysis, some mutants were characterized as PAC1 receptor antagonists, e.g. the 44 -amino acid polypeptide called M-65 [21]. Studies of the biological effects of PACAP revealed that it enhanced the permeability-inducing effects of bradykinin in the skin of rabbits [22,23] and rats [24]. Further, in the human nose, PACAP-38 caused extravasation of plasma albumin [25]. It may thus be expected that PACAP and maxadilan could have the same effects in the hamster cheek pouch (HCP), a skinlike tissue without glands and hair follicles.

Among the myriad of vasoactive and immunomodulatory compounds found in sand fly salivary glands [26], maxadilan and adenosine injection can provoke systemic effects through the induction of arteriolar vasodilation and the stimulation of pro- or anti-inflammatory mediators, e.g. TNF- $\alpha$, IL- 6 or IL-10 [27-29].

There is much experimental evidence that vasodilation will only enhance extravasation of large molecules (plasma leakage) if there is a concomitant stimulation of postcapillary endothelial cells by the vasodilator or by some other agent. Although sand fly-injected parasites may increase their infectivity at the expense of the vasodilating effects of maxadilan [12], it remains to be determined if this vasoactive compound may independently promote plasma leakage via activation of $\mathrm{PAC}-1$ receptors expressed by neutrophils and monocytes [30,31].

Here, we used HCP as a model to investigate if salivary gland homogenate (SGH) may evoke arteriolar dilation and extravasation of plasma from postcapillary venules, and then characterized the vasoactive responses induced by maxadilan and PACAP-38. Apart from their predicted vasodilatory effects, SGH, maxadilan and PACAP-38 were able to independently evoke plasma leakage in the cheek pouch. The finding that the M-65 mutant of maxadilan reduced both vasodilation and plasma leakage induced by SGH or maxadilan suggests that their vasoactive and pro-inflammatory effects are at least partially mediated by activation of $\mathrm{PAC1}$ receptors.

\section{Animals and Methods}

Sand Flies and Preparation of SGH

L. longipalpis sand flies were obtained from the Camará colony maintained at the Department of Entomology, Fundação Oswaldo Cruz, Rio de Janeiro, Brazil. Salivary glands from female sand flies, 3-5 days old, non-blood fed, were dissected out in cold phosphate-buffered saline ( $\mathrm{pH}$ 7.0). Glands were sonicated for 3 cycles at $35 \%$ amplification (Ultrasonic processor $750 \mathrm{~W}$ ), centrifuged at $8,000 \mathrm{rpm}$ and supernatants stored at $-80^{\circ} \mathrm{C}$ until thawed for use.

Intravital Digital Microscopy of the HCP

Hamsters were anesthetized by intraperitoneal injection of sodium pentobarbital supplemented with intravenous $\alpha$-chloralose $(2.5 \% \mathrm{~W} / \mathrm{V}$ in saline solution) through a femoral vein catheter. A tracheal cannula (PE 190) was inserted to facilitate spontaneous breathing, and the body temperature was maintained at $37^{\circ} \mathrm{C}$ using a heating pad connected to a rectal thermistor probe. HCP was prepared and used for intravital microscopy as previously reported [32-34]. Briefly, the cheek pouch was everted and mounted on a microscope stage, and an area of about $1 \mathrm{~cm}^{2}$ was prepared for intravital microscopy observations of the microcirculation. Thirty minutes after completing the preparation, fluorescein-labeled dextran (100 mg/kg body weight; FITC-dextran, molecular weight $=150 \mathrm{kDa}$; TdB Consultancy, Uppsala, Sweden) was intravenously injected as a macromolecular tracer. HCP were continuously superfused with a HEPES-bicarbonate-buffered saline solution (pH 7.4; composition in mM: $110.0 \mathrm{NaCl}, 4.7 \mathrm{KCl}, 2.0 \mathrm{CaCl}_{2}$, 1.2 $\mathrm{MgSO}_{4}, 18.0 \mathrm{NaHCO}_{3}, 15.39$ HEPES and 14.61 Na HEPES) at a constant rate of $5 \mathrm{ml} / \mathrm{min}$. The superfusion solution was bubbled with a $5 \% \mathrm{CO}_{2}-95 \% \mathrm{~N}_{2}$ mixture to maintain a low physiological oxygen level around the cheek pouch. A heater was adjusted to maintain the superfusion temperature at $35^{\circ} \mathrm{C}$. HCP microcirculation was assessed using an Axioskop 40 microscope with a $\times 4$ objective and $\times 10$ oculars (Zeiss, Oberkochen, Germany) equipped with appropriate filters $(490 / 520 \mathrm{~nm})$ for observations of epiluminescence fluorescence. Images were captured with a digital camera (AxioCamHRc; Zeiss) and processed with AxioVision software (AxioVision 4.4; Zeiss). Each AxioCamHRc image 
of a $5-\mathrm{mm}^{2}$ area consisted of $1,388 \times 1,040$ pixels. Image width was 1,388 pixels or $2,500 \mu \mathrm{m}$ and image height was 1,040 pixels or $2,000 \mu \mathrm{m}$. Each recorded image in the computer consisted of 8.37 $\mathrm{MB}$ and was stored concomitant with technical data, and date and hour of exposure. A typical experiment required 200$300 \mathrm{MB}$. AxioVision 4.4 was used for measurements of arteriolar diameter and total fluorescence in a representative rectangular area $\left(5 \mathrm{~mm}^{2}\right)$ of the prepared HCP $\left(\sim 1 \mathrm{~cm}^{2}\right)$, with one or two arterioles ranging from 20 to $60 \mu \mathrm{m}$ in diameter being suitable for measurements. For group comparisons, the diameter at the end of the 30 -min control period (time 0 ) was set to $100 \%$. Following intravenous injection of FITC-dextran, images of the microcirculation $\left(5 \mathrm{~mm}^{2}\right)$ were recorded at 5-min intervals during the entire experimental period and stored in a computer. A standardized exposure time (100 ms) was used in all experiments, and background fluorescence was assessed before FITC-dextran injection with no light source activated ( $\sim 60$ fluorescence units) and with the UV light ( $275 \pm 70$ fluorescence units, $\mathrm{n}=68$ ). The standardized dose of FITC-dextran ( $100 \mathrm{mg} / \mathrm{kg}$ body weight) resulted in a total fluorescence of 2,238 \pm 942 units $(\mathrm{n}=68)$ in the $5-\mathrm{mm}^{2}$ area $30 \mathrm{~min}$ after intravenous injection. The recorded 30 -min fluorescence in each experiment was adjusted to 2,000 fluorescent units for statistical reasons. The original method for studies on microvascular permeability changes in the HCP that implied counting of sites (leaks) with extravasation of FITC-dextran in postcapillary venules [32] has been verified in several studies by measuring FITC-dextran concentrations of the superfusion buffer [35-40]. In order to validate our present modification of the original method involving a digital camera connected to a microscope (AxioVision and AxioCam $\mathrm{HRc}$ ) for fluorescence measurements in a rectangular area $\left(5 \mathrm{~mm}^{2}\right)$ of the HCP $\left(\sim 1 \mathrm{~cm}^{2}\right)$, the superfusion solution was sampled every $5 \mathrm{~min}$ during the hour following the 2 -min application of histamine $\left(10^{-5} \mathrm{M}\right)$. FITC-dextran concentrations of the superfusion solution were determined by fluorimetry (Hitachi FH 4500; Hitachi, Tokyo, Japan).

After FITC injection (100 mg/kg body weight) and an initial 30 -min control period to establish normal blood flow and vascular permeability conditions, superfusion of the HCP was interrupted, and agents diluted to appropriate testing concentrations in a volume of $250 \mu \mathrm{l}$ saline were applied on the dissected HCP area during $9 \mathrm{~min}$ until superfusion was restarted. This procedure has been found to cause no significant alterations in arteriolar diameter or fluorescence upon restart of the interrupted superfusion. SGH equal to half (SGH-0.5) or one salivary gland (SGH-1), according to the dose used by Morris et al. [41] in 2001, were topically applied on the HCP for 9 min after interruption of superfusion. The concentrations of maxadilan (33 and $67 \mathrm{nM}$ ) were determined in pilot experiments, with vasodilation and plasma leakage being similar to the effects of SGH. The maxadilan mutant M-65 was applied at a concentration of $8 \mu \mathrm{M}(120$ times the concentration of $67 \mathrm{nM}$ maxadilan) and PACAP-38 was applied at $50 \mathrm{nM}$ in $250 \mu \mathrm{l}$ of saline. Tested compounds from stock solutions kept on ice were immediately diluted in $250 \mu$ l of saline prior to their application on the HCP.

Thirteen groups of male hamsters (68 hamsters in toto) were studied: group 1 (control group; $\mathrm{n}=6)-250 \mu \mathrm{l} \mathrm{PBS}$ at $0 \mathrm{~min}$; group $2(\mathrm{n}=6)$ - SGH-0.5; group $3(\mathrm{n}=5)-\mathrm{SGH}-1$, group $4(\mathrm{n}=$ $5)$ - $33 \mathrm{nM}$ maxadilan in PBS; group $5(\mathrm{n}=7)-67 \mathrm{nM}$ maxadilan in PBS; group $6(n=5)$ - local treatment first with $8 \mu M$ M-65 and then with M-65 + maxadilan; group $7(n=5)-8 \mu \mathrm{M} M-65+\mathrm{SGH}-$
1 followed by SGH-1; group $8(n=5)-250 \mu$ l of a 50 nM PACAP38 solution in saline; group $9(\mathrm{n}=4)$ - treatment with $4 \mu \mathrm{M}$ of PACAP6-38, a competitive PAC1 receptor antagonist, 2 min prior to the application of $67 \mathrm{nM}$ maxadilan or $250 \mu \mathrm{l}$ PBS ( $\mathrm{n}=3$, control), and group $10(\mathrm{n}=3)-8 \mu \mathrm{M}$ M-65 given 2 min prior to PACAP-38 application (50 nM). Three further groups were studied to evaluate the role of bradykinin, histamine and nitric oxide in SGH-induced effects: group $11(\mathrm{n}=5)$ - treatment with the bradykinin-2-receptor antagonist HOE-140 $(0.5 \mu \mathrm{M}) 5 \mathrm{~min}$ prior to SGH-0.5 application; group $12(n=5)$ - treatment with the antihistamine mepyramine $(25 \mu \mathrm{M})$ prior to SGH-0.5 application, and group $13(\mathrm{n}=4)$ - treatment with L-nitro-arginine (L-NA, 10 $\mu \mathrm{M}) 5 \mathrm{~min}$ prior to SGH-0.5. Recombinant maxadilan and the maxadilan antagonist M-65 were obtained as described [21]. PACAP-38 was from Sigma (St. Louis, Mo., USA), EUA and PACAP6-38 were from Bachem (Bubendorf, Switzerland).

\section{Statistical Analyses}

Statistical evaluation was performed with ANOVA followed by Student's t test (between groups) and paired t test (within groups). A p value of 0.05 or less was considered to indicate a statistically significant difference. Data are presented as means \pm SEM.

\section{Results}

\section{Fluorescence Increase in the HCP and in the}

Superfusion

Parallel measurements of histamine-induced plasma leakage with the digital camera and of FITC-dextran concentrations of the superfusion fluid leaving from the microscope stage with the mounted cheek pouch showed that measurements in a $5-\mathrm{mm}^{2}$ area of the HCP microcirculation were representative of changes in the entire HCP preparation, as reflected by FITC-dextran concentrations in the superfusion fluid (fig. 1,2). The maximal response to $10^{-5} \mathrm{M}$ histamine for $2 \mathrm{~min}$ detected by the digital camera occurred approximately $10 \mathrm{~min}$ earlier than the peak value of FITC-dextran (expressed in $\left.\mathrm{pg} \cdot \mathrm{ml}^{-1}\right)$. A linear regression analysis after adjusting maximal response for this time shift revealed a highly significant linear correlation between fluorescence of the $5-\mathrm{mm}^{2}$ area and the FITC-dextran concentrations ( $\mathrm{n}=12, \mathrm{r}=0.973$ and $\mathrm{p}=0.00001$ ). Thus, measurements of fluorescence in a restricted area of the HCP reflected histamine-induced vascular permeability changes in the entire HCP preparation.

\section{Arteriolar Dilation Induced by SGH and Maxadilan}

At end of the initial 30-min control period, arteriolar diameter varied from $38.9 \pm 16.9 \mu \mathrm{m}$ (mean $\pm \mathrm{SD}$ ) in the mepyramine group to $51.8 \pm 11.5 \mu \mathrm{m}$ in the $67-\mathrm{nM}$ maxadilan group. There were no statistically significant differences in these diameters between groups (fig. $4 ; \mathrm{p}>0.1$ ). 

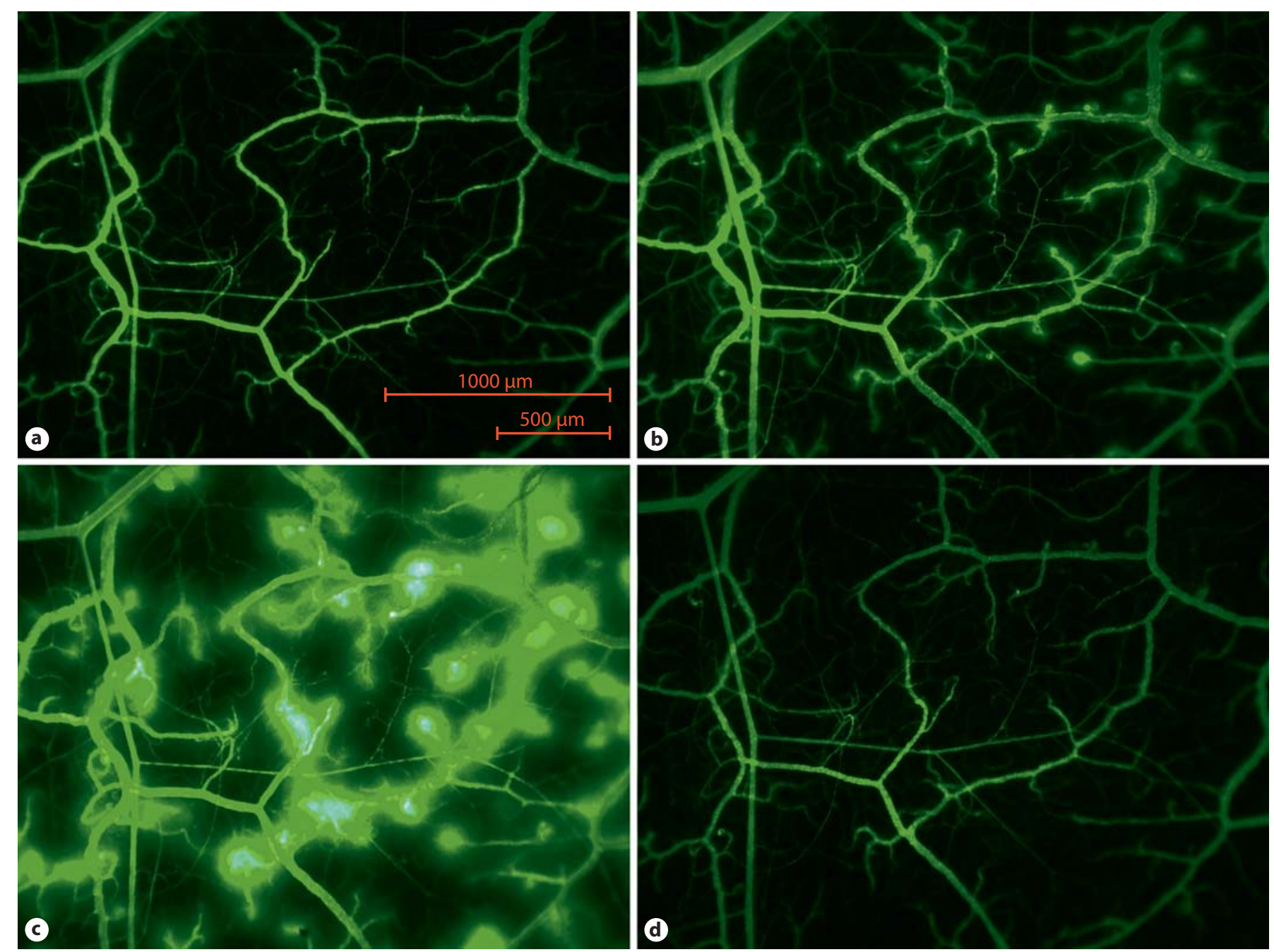

Fig. 1. Four images of the $5-\mathrm{mm}^{2}$ rectangular HCP areas that were used for fluorescence measurements (fig. 2) prior to (a), and 1 (b), 4 (c) and $30 \mathrm{~min}(\mathbf{d})$ after histamine application.

Fig. 2. Fluorescence in a $5-\mathrm{mm}^{2}$ rectangular HCP area (fig. 1) and FITC-dextran concentrations in the superfusion of the same HCP (pg/ml superfusion). Histamine $\left(10^{-5} \mathrm{M}\right)$ was applied for $2 \mathrm{~min}$, resulting in parallel increases in fluorescence of the cheek pouch and of the FITC-dextran concentration in the superfusion fluid leaving from the microscope stage with the mounted cheek pouch. Letters and arrows indicate the fluorescence measured prior to (a), and 1 (b), 4 (c) and 30 min after (d) histamine application. Peak values of the two curves differed by $\sim 10 \mathrm{~min}$. A linear regression analysis after adjustment for this time shift of maximal response revealed a highly significant linear correlation between fluorescence of the $5-\mathrm{mm}^{2}$ area and FITC-dextran concentrations ( $\mathrm{n}=12, \mathrm{r}=0.973$ and $\mathrm{p}=0.00001)$.

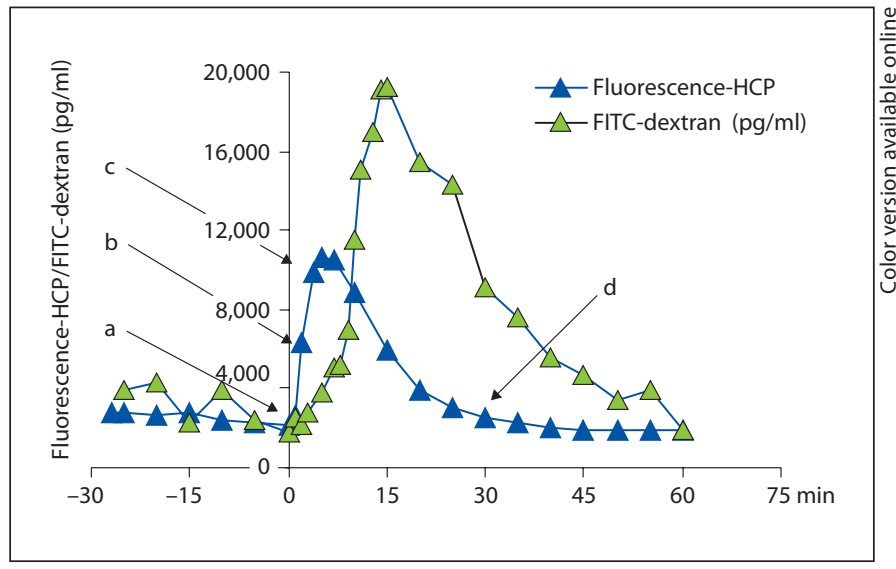

Svensjö/Saraiva/Bozza/Oliveira/Lerner/ Scharfstein 


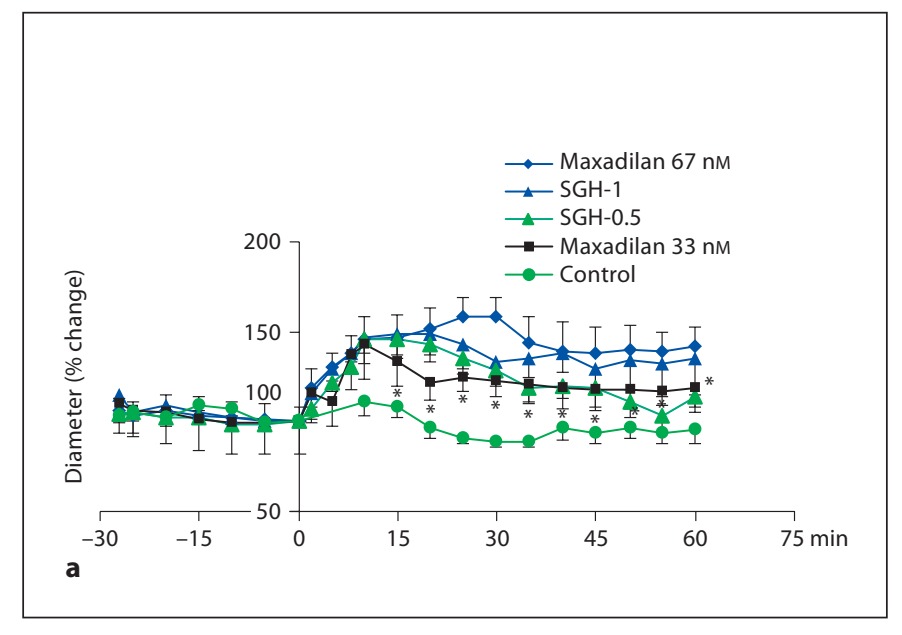

Fig. 3. a Changes in arteriolar diameter (means \pm SEM and diameter at time $0=100 \%$ ) measured using intravital microscopy in five groups of hamsters. Two groups were exposed to topical applications of SGH in $250 \mu \mathrm{l}$ normal saline for $9 \mathrm{~min}$ (SGH-0.5, $\mathrm{n}=6$, and SGH-1, $\mathrm{n}=5$ ). The fourth and fifth group were given topical applications of maxadilan $(33 \mathrm{nM}, \mathrm{n}=5$, and $67 \mathrm{nM}, \mathrm{n}=7$ ) in $250 \mu \mathrm{l}$ saline, and the sixth group $250 \mu \mathrm{l}$ of normal saline in a similar way $(n=6)$. The four treated groups showed rapid and long-lasting dilation $(\mathrm{p}<0.05)$ above the saline control group until $60 \mathrm{~min}$. There was a significant difference $(\mathrm{p}<0.05)$ between the 33 - and the $67-\mathrm{nm}$ maxadilan groups at 15 to $60 \mathrm{~min}$ after

Topical application of $250 \mu \mathrm{l}$ of SGH- 0.5 or the equivalent amount of SGH-1 on the HCP caused an immediate and long-lasting arteriolar dilation which was significantly different $(\mathrm{p}<0.05)$ from the saline application control value at $2 \mathrm{~min}$, reached its maximum after $10-15$ min and remained above the initial control value until 60 min, when it returned to values before application. The dilation induced by SGH-1 was not significantly larger than that of SGH-0.5, although it remained above the values before application at $60 \mathrm{~min}$ (fig. 3a).

Maxadilan also caused immediate and long-lasting arteriolar dilation similar to that observed with SGH, which started to decrease $30 \mathrm{~min}$ after application of 33 nM maxadilan, while it remained $30 \%$ above the initial control value in the group receiving $67 \mathrm{nM}$ maxadilan . Arteriolar dilation in the $67-\mathrm{nM}$ maxadilan group was significantly greater $(\mathrm{p}<0.05)$ than in the $33-\mathrm{nm}$ maxadilan group from 15 min after challenge up to the final measurements (fig. 3a). The dilation curve induced by SGH- 0.5 was almost identical to that produced by $33 \mathrm{~nm}$ maxadilan (fig. 3a).

Salivary Gland Homogenates and Maxadilan Cause Plasma Leakage

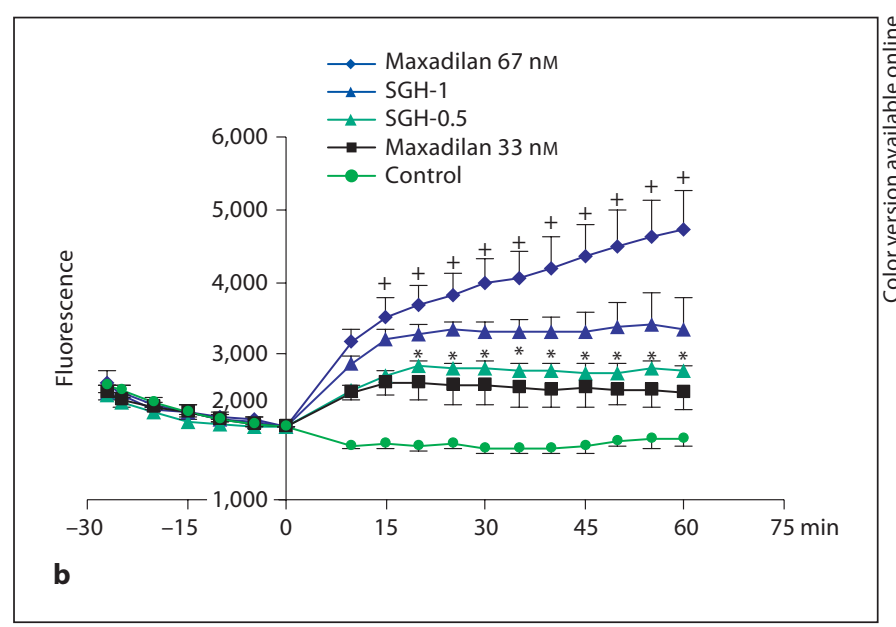

stimulation. b Fluorescence (mean \pm SEM) measured using intravital microscopy in five groups of hamsters with the same drug treatment and groups as in $\mathbf{a}$. The four treated groups were significantly different $(\mathrm{p}<0.05)$ from the control group 10-60 min after stimulation, and the larger dose of salivary homogenate (SGH-1) caused more plasma leakage than the smaller dose (SGH$0.5 ;{ }^{*} \mathrm{p}<0.05$ vs. SGH-1). There was no difference between the SGH- 0.5 group and the $33-\mathrm{nM}$ maxadilan group $(\mathrm{p}>0.2)$, but the effects induced by $67 \mathrm{nM}$ maxadilan exceeded those induced by $33 \mathrm{nM}\left({ }^{+} \mathrm{p}<0.05\right.$ vs. $\left.33 \mathrm{nM}\right)$.

\section{Plasma Leakage Induced by SGH, Maxadilan and PACAP-38}

Topical application of SGH- 0.5 caused an increase in fluorescence which peaked after $20-25 \mathrm{~min}$ and plateaued until $60 \mathrm{~min}$ after its application, although $30 \mathrm{~min}$ after application arteriolar dilation had returned to values obtained before application. Consequently, the fluorescence which was still elevated after maximal dilation had been reached due to plasma extravasation and not vasodilation. The increase in fluorescence following SGH- 1 was significantly larger $(20 \%, \mathrm{p}<0.05)$ than that of SGH-0.5 (fig. 3b).

Both doses of maxadilan caused long-lasting increases in fluorescence that remained elevated after maximal dilation had been reached, thus showing that fluorescent plasma continued to leak from postcapillary venules during the entire experimental period (fig. 3b). Maxadilan (67 nM) caused 10-40\% more plasma leakage than SGH0.5 and SGH-1 at the same degree of dilation, but the effect of $33 \mathrm{nM}$ of maxadilan was similar to that of SGH-0.5 or $10 \%$ below ( $p>0.2$ for differences between curve values). A second application of SGH- 0.5 after 60 min caused 


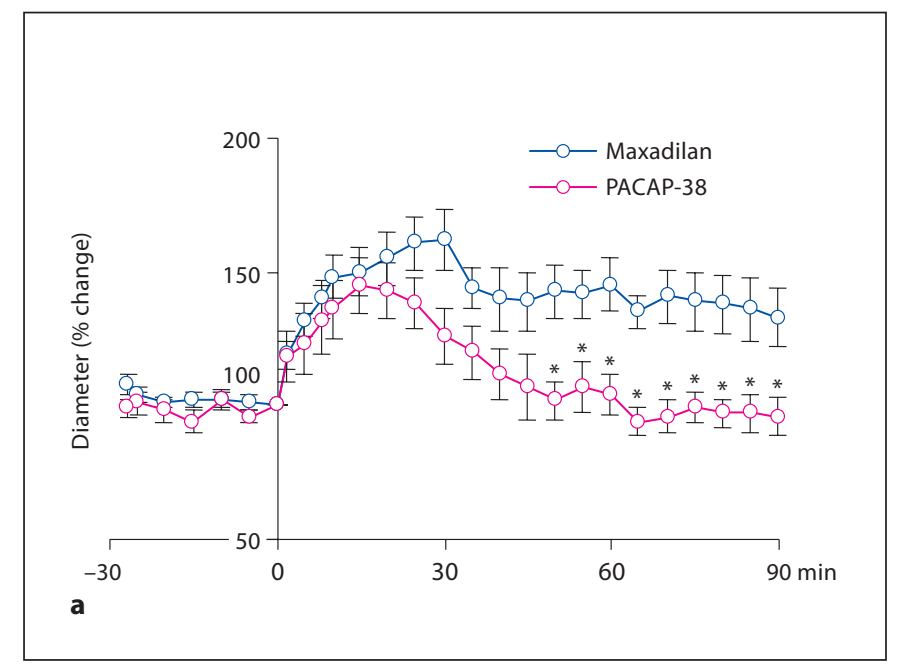

Fig. 4. a Changes in arteriolar diameter (means \pm SEM; diameter at time $0=100 \%$ ) assessed using intravital microscopy in hamsters exposed to topical applications of $50 \mathrm{~nm}$ PACAP-38. Maxadilan (67 nM)-induced effects were shown for comparison (fig. 3a); maxadilan caused a long-lasting dilation that remained above that induced by PACAP-38 50-60 min after its application $\left({ }^{*} \mathrm{p}<\right.$

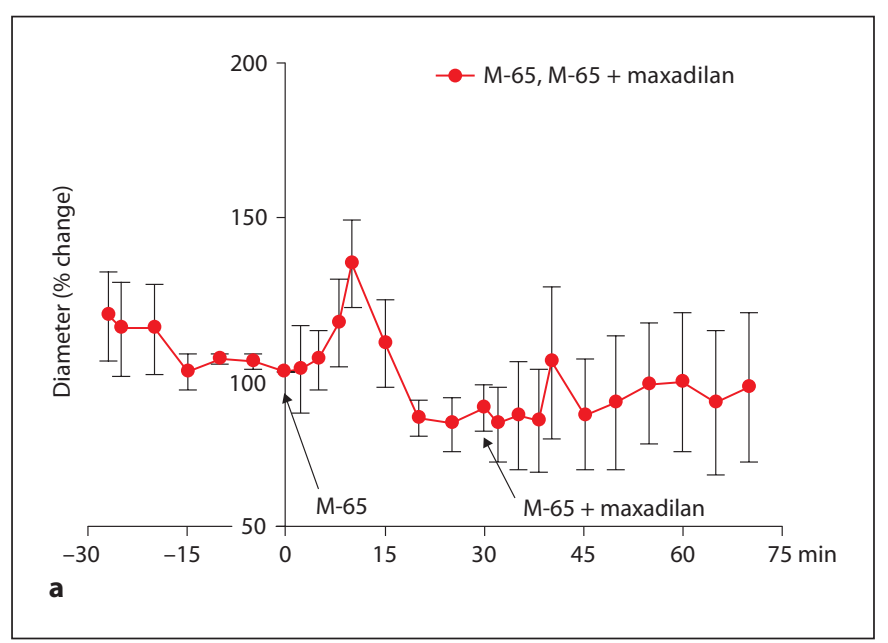

Fig. 5. a Arteriolar diameter changes (mean \pm SEM) in 4 hamsters following application of $8 \mu \mathrm{M}$ M-65 and, after $30 \mathrm{~min}, \mathrm{M}-65$ and $67 \mathrm{nM}$ maxadilan. There was only a short-lasting vasodilation after the first M- 65 application, but not after the M-65-maxadilan combination. $\mathrm{n}=4$. $\mathbf{b}$ Fluorescence assessed using intravital mi-

dilation of the same magnitude as the first application, but evoked no significant changes in plasma leakage (data not shown). PACAP-38 (50 nM) caused dilation and plasma leakage similar to that seen with maxadilan.

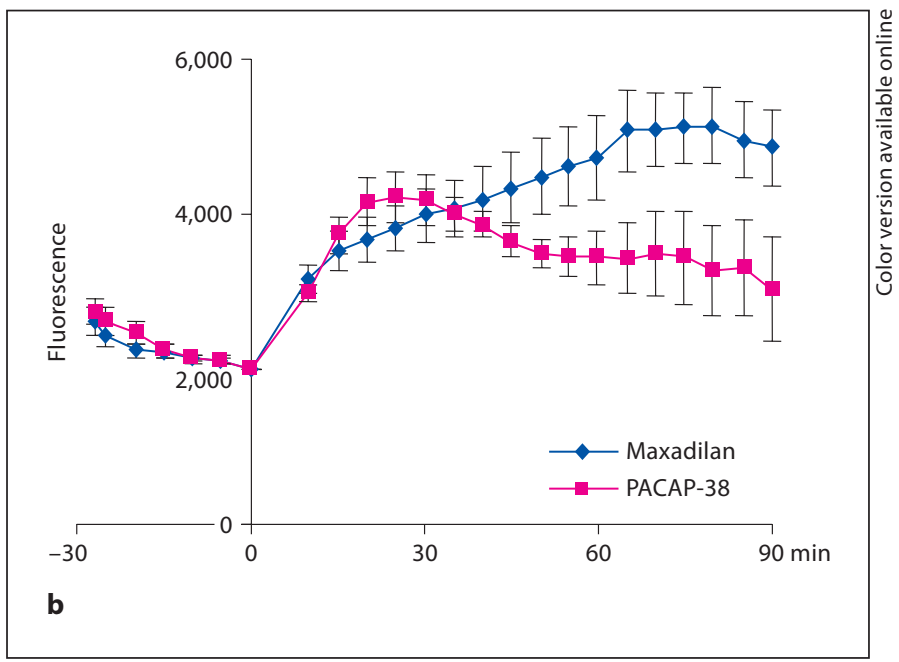

0.05). b Fluorescence (mean \pm SEM) measured using intravital microscopy in hamsters exposed to topical applications of $50 \mathrm{nM}$ PACAP-38. Maxadilan (67 nM)-induced effects (fig. 3b) are shown for comparison. There were no significant differences $(\mathrm{p}>0.05)$ between the maxadilan $(n=7)$ and the PACAP-38 group $(n=5)$.

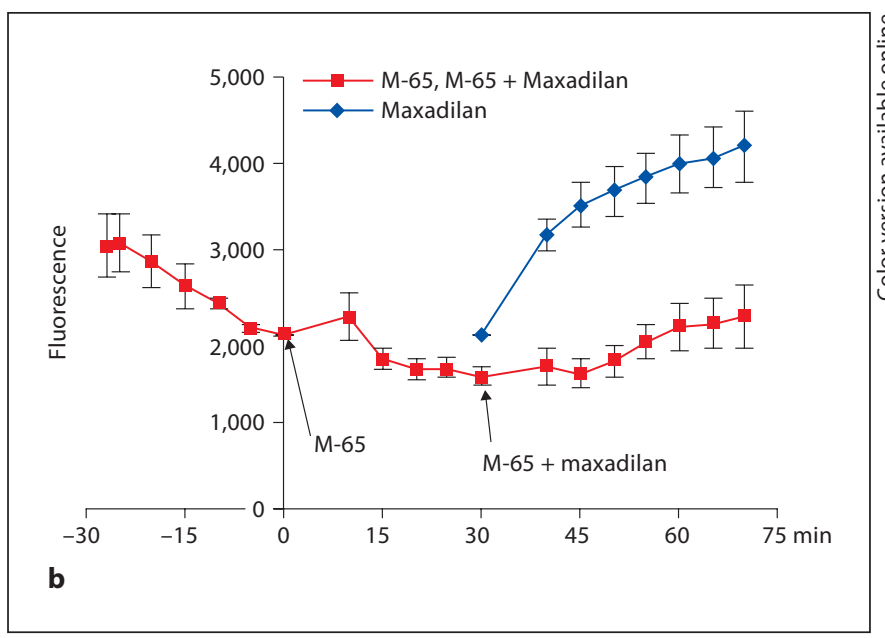

croscopy in 4 hamsters showing no increase in plasma leakage after $8 \mu \mathrm{M}$ M-65 and inhibition of maxadilan-induced plasma leakage by $8 \mu \mathrm{M}$ M-65 applied prior to $67 \mathrm{nM}$ maxadilan. The effect of maxadilan (fig. $3 \mathrm{~b}, \mathrm{n}=7$ ) was shown for comparison.

Effects of M-65 on SGH-, Maxadilan- and PACAP-38Induced Dilation and Plasma Leakage

M-65 is a maxadilan-derived mutant peptide (deletion of amino acids $25-41$ in the maxadilan molecule) 


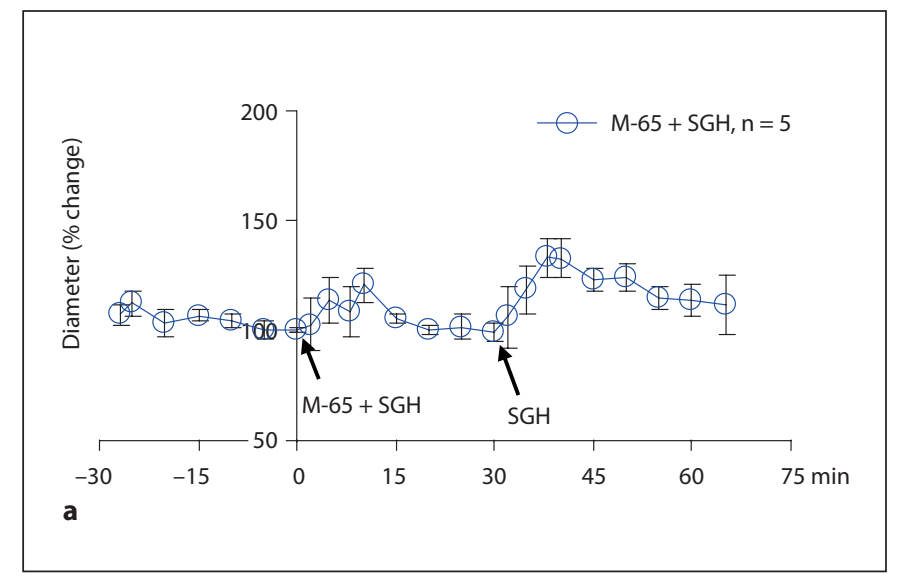

Fig. 6. a Mean arteriolar diameter changes (\% of diameter at time 0 ) in 5 hamsters following application of $8 \mu \mathrm{M}$ M- $65+$ SGH, with a temporary inhibition of SGH-induced vasodilation by M-65. The vasodilation induced by SGH without M- 65 was of the same magnitude as that for SGH-1 (fig. 3a). b Fluorescence measured

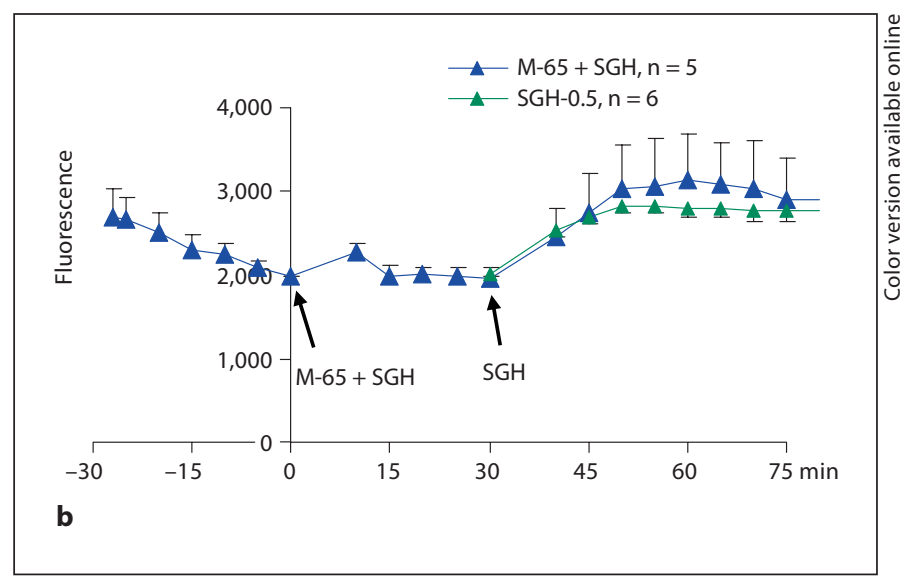

using intravital microscopy in 5 hamsters revealed no consistent increase in plasma leakage after combined application of M-65 + SGH-1, but an increase following SGH-1 30 min after M-65, thus a temporary inhibition of SGH-induced plasma leakage. The effect of SGH-0.5 (fig. 3b) was shown for comparison. which has been shown to bind to PAC-1 receptors generating a maxadilan antagonistic effect $[16,21]$. When an $8-\mu \mathrm{M}$ solution of M-65 was applied to the cheek pouch, there was a short-lasting dilation (fig. 5a), but there was no increase in plasma leakage. Furthermore, when M-65 was given prior to maxadilan, it totally blocked its vasodilator and plasma leakage effects (fig. 5b). M-65 also inhibited the vasodilation and plasma leakage caused by SGH (fig. 6). The inhibition resolved after a 30-min washout period, and the response to a second dose of SGH without M-65 was of the same magnitude as that induced by SGH (fig. 3b). In three experiments, $8 \mu \mathrm{M}$ M-65 was given prior to PACAP-38 application and there was no difference compared with the effects of PACAP38 (fig. 7).

\section{Effects of PACAP6-38 on Maxadilan-Induced}

Dilation and Plasma Leakage

PACAP6-38 is a competitive antagonist to PACAP-38, missing a sequence of 6 amino acids. Topical application of $4 \mu \mathrm{M}$ PACAP6-38 prior to $67 \mathrm{nM}$ maxadilan resulted in no arteriolar dilation (fig. 8a) and an inhibition of the plasma leakage effect of maxadilan $35 \mathrm{~min}$ after its application (fig. $8 \mathrm{~b}$ ). The inhibition was not complete, which was confirmed by measurements of dilation suggesting that PACAP6-38 has a slight agonistic effect on plasma leakage. Application of 0.4 and $4 \mu \mathrm{M}$ PACAP6-38 resulted in similar arteriolar dilation changes as seen after
$4 \mu \mathrm{M}$ PACAP6-38 + maxadilan. There was no plasma leakage induced by $400 \mathrm{nM}$ PACAP6-38, but the effect of $4 \mu \mathrm{M}$ was similar to that exerted by PACAP6-38 + maxadilan.

\section{Effects of HOE-140, Mepyramine and L-NA}

on SGH- and Maxadilan-Induced Dilation and

Plasma Leakage

Mean basal arteriolar diameter was $47.8 \pm 4.1 \mu \mathrm{m}$ in the saline control group, $39.9 \pm 6.4 \mu \mathrm{m}$ in the SGH-0.5 group, $46.2 \pm 4.5 \mu \mathrm{m}$ in the SGH-1 group, $46.5 \pm 3.9$ $\mu \mathrm{m}$ in the HOE-140 group, $38.9 \pm 7.5 \mu \mathrm{m}$ in the mepyramine group and $44.4 \pm 2.2 \mu \mathrm{m}$ in the L-NA group. There were no significant differences in basal diameters in these groups. Treatment of the HCP with HOE-140, mepyramine or L-NA prior to application of SGH-0.5 had no effect on arteriolar dilation, but resulted in a $20 \%$ reduction in plasma leakage $(\mathrm{p}<0.05)$ in the HOE-140treated group (fig. 9). A second application, of SGH-0.5 induced dilation similar to the first application, but no further increase could be observed in plasma leakage (data not shown). Similar to SGH-0.5 experiments, L-NA applied prior to maxadilan did not inhibit maxadilan-induced effects (data not shown). The possible inhibition of the maxadilan-induced dilation and plasma leakage by the bradykinin antagonist HOE-140 was tested in 3 hamsters: 1 treated with maxadilan (positive control; fig. 3) and 2 with $0.5 \mu \mathrm{M}$ HOE-140 during the $5 \mathrm{~min}$ prior to 


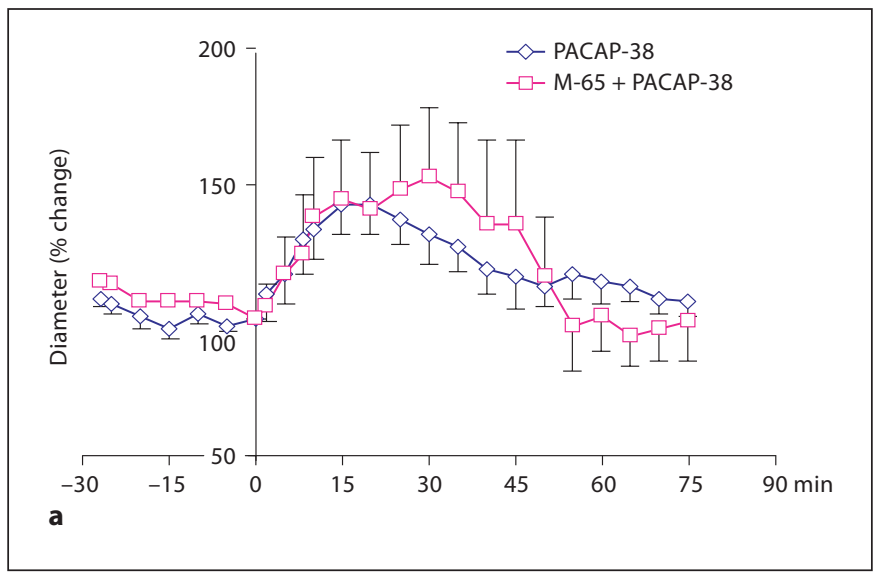

Fig. 7. a Mean arteriolar diameter changes (\% of diameter at time 0 ) in 3 hamsters following application of $8 \mu \mathrm{M} M-65+50 \mathrm{nM}$ PACAP-38, with no difference compared with the effect of PACAP-38. The results of 5 hamsters given $50 \mathrm{~nm}$ PACAP-38 (fig. 4a) were shown for comparison. b Using fluorescence mea-

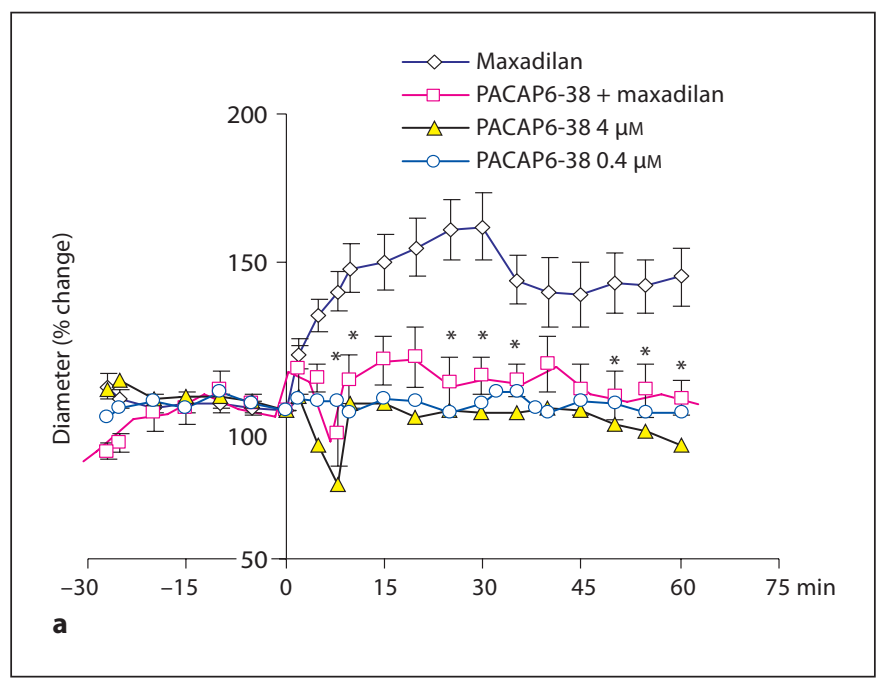

Fig. 8. a Arteriolar diameter changes (\% of diameter at time 0 ; mean \pm SEM) in 4 hamsters following application of $4 \mu \mathrm{M}$ PACAP6-38 + 67 nM maxadilan, showing significant inhibition of maxadilan-induced dilation $\left({ }^{*} \mathrm{p}<0.05\right)$. Results in hamsters given $4(\mathrm{n}=3)$ or $0.4 \mu \mathrm{M}$ PACAP6-38 $(\mathrm{n}=1)$ were not different from those treated with PACAP6-38 + maxadilan. The results in 7 hamsters given $67 \mathrm{nM}$ maxadilan (fig. 3a) were shown for com-

and $30 \mathrm{~min}$ after maxadilan application. There were neither differences in the vasodilatory responses nor in the plasma leakage response between these 3 hamsters (data not shown).

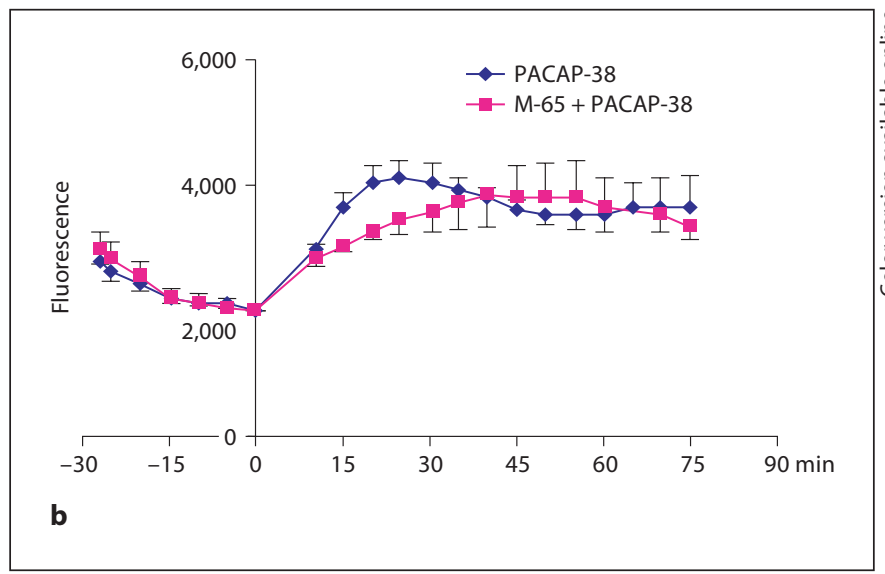

surements in 3 hamsters, plasma leakage did not differ after application of $8 \mu \mathrm{M} M-65+50 \mathrm{nM}$ PACAP-38 and PACAP-38. The results of 5 hamsters given $50 \mathrm{nM}$ PACAP-38 (fig. $4 \mathrm{~b}$ ) were shown for comparison.

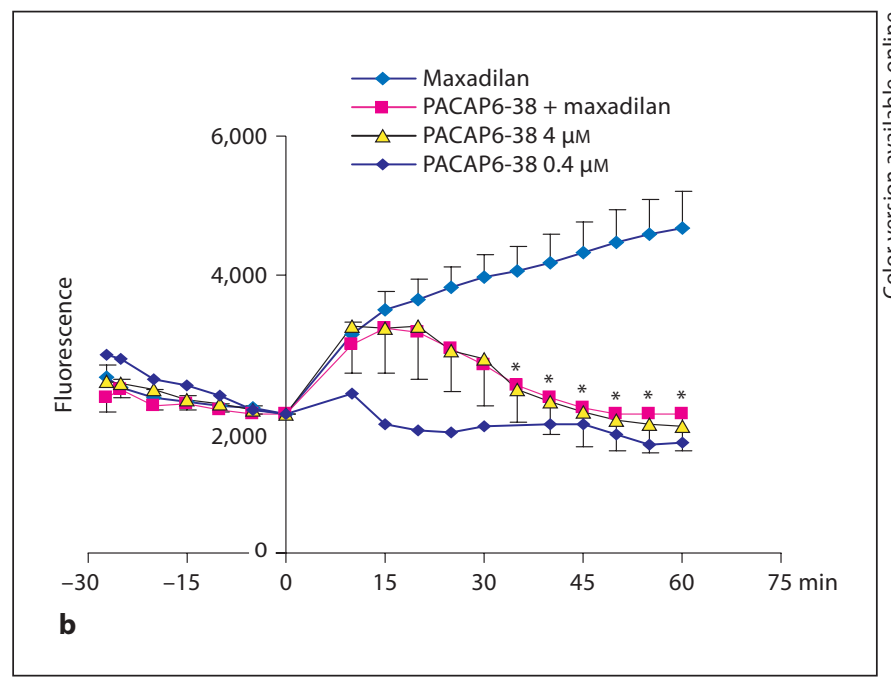

parison. b Fluorescence measured in 4 hamsters showing a temporary increase in plasma leakage after application of $4 \mu \mathrm{M}$ PACAP6-38 + 67 nM maxadilan followed by a significant inhibition of the maxadilan-induced plasma leakage $\left({ }^{*} \mathrm{p}<0.05\right) 35-60$ min after application. A similar increase in plasma leakage was seen with $4 \mu \mathrm{M}$ PACAP6-38, but there was no increase after application of $0.4 \mu \mathrm{M}$ PACAP6-38 (means \pm SEM).

\section{Discussion}

FITC-dextran has been well established as a plasma marker to measure vascular permeability increase in postcapillary venules $[33,42]$. Several studies using FITC- 


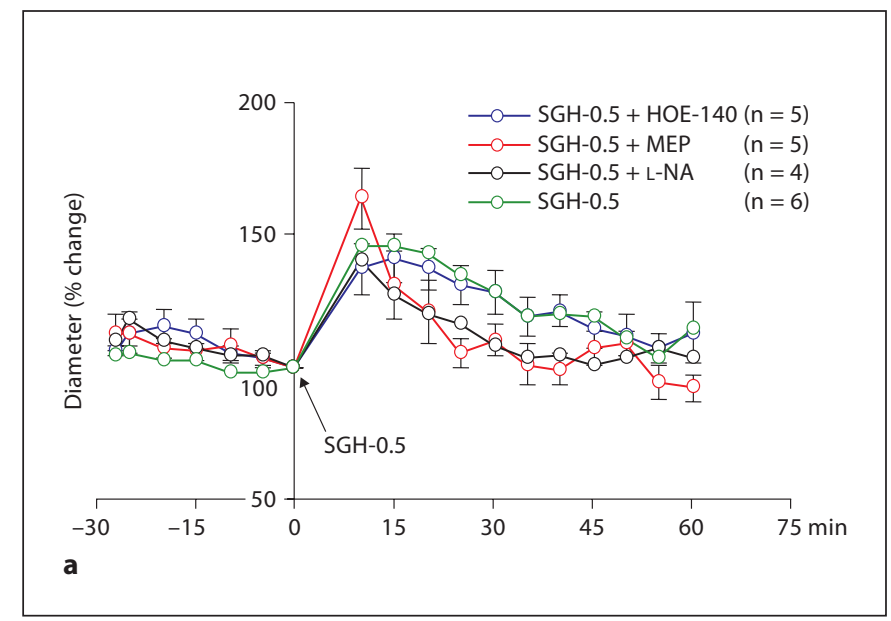

Fig. 9. a Changes in arteriolar diameter (means \pm SEM; diameter at time $0=100 \%$ ) measured using intravital microscopy in four groups with 4-6 hamsters each exposed to topical applications of $\mathrm{SGH}$ in $250 \mu \mathrm{l}$ normal saline (SGH-0.5). Prior to application of SGH-0.5, the prepared cheek pouches were locally treated with HOE-140 $(0.5 \mu \mathrm{M})$, mepyramine $(25 \mu \mathrm{M})$ or L-NA $(10 \mu \mathrm{M})$ for 5 min without interruption of superfusion. SGH-0.5-induced dilation (fig. 3a) was shown for comparison. Dilation did not sig-

dextran to measure microvascular permeability increase or plasma leakage have shown that the number of leaks counted microscopically was correlated with the clearance of FITC-dextran from the cheek pouch measured in the superfusion fluid [35-39]. A linear correlation between fluorescence intensity on a TV monitor and FITCdextran vascular and tissue concentrations in the HCP has also been found [40]. In the present study, a digital camera and computer software (AxioVision) were used to measure fluorescence in a rectangular area of $5 \mathrm{~mm}^{2}$. In order to validate this refinement of the original method of measuring plasma leakage in the microcirculation, FITC-dextran concentrations in the superfusion solution were determined concomitantly with digital camera fluorescence recordings before and after histamine application. These experiments confirmed that the dynamics of the recorded fluorescence corresponded with FITC-dextran concentrations, as a linear correlation was obtained between fluorescence and the concentration of FITCdextran in the superfusion fluid. Therefore, our results demonstrate that the fluorescence measurements in the restricted area were representative of the vascular permeability changes in the entire cheek pouch preparation.

The vasodilatory effects of salivary gland homogenates and their capacity to enhance Leishmania infectivity have already been recognized $[5,12]$. Apart from the

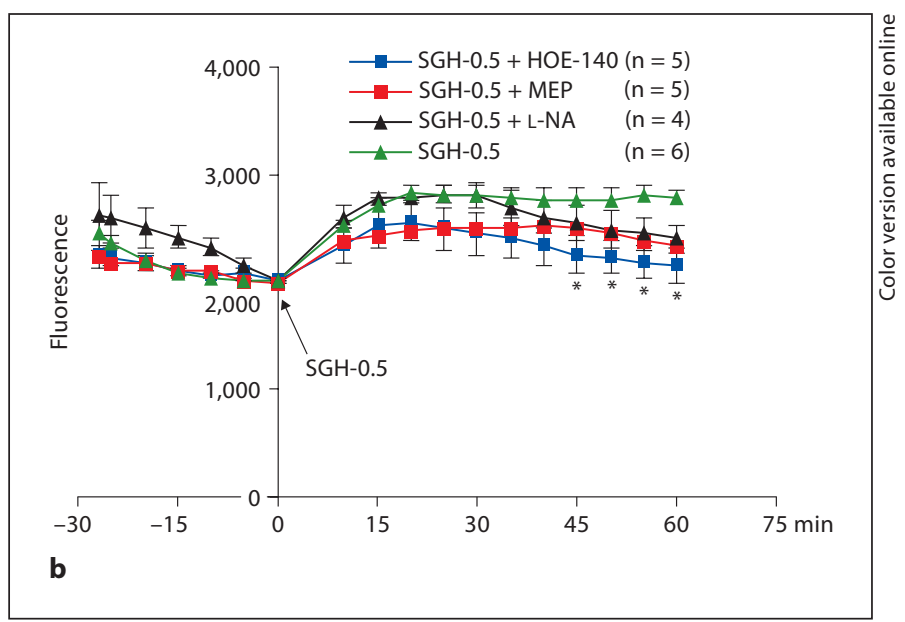

nificantly differ in the four groups. b Fluorescence (means \pm SEM) measured using intravital microscopy in four groups with 4-6 hamsters each exposed to topical applications of drugs (see fig. 9a). SGH-0.5-induced increases in plasma leakage (fig. 3b) were shown for comparison. Increases in fluorescence did not different in the four treatment groups until 45 min after SGH application, when the HOE-140 group showed a $20 \%$ reduced plasma leakage $\left({ }^{*} \mathrm{p}<0.05\right)$ compared with the SGH- 0.5 group.

vasodilatory peptide maxadilan, a broad range of proteins has been identified in the salivary gland of $L$. longipalpis [26], possibly indicating that although maxadilan might be the major vasodilator of saliva, other proteins may also contribute to the pro-inflammatory effects of $L$. longipalpis saliva. As a first approach, the immediate inflammatory changes in SGH isolated from the sand fly $L$. longipalpis were compared with those induced by recombinant maxadilan immediately after application to the HCP microcirculation, a skin-like tissue. However, it remains to be determined how the parasites benefit from these pro-inflammatory or vasoactive effects at the moment of infection. The enhancement could be due to arteriolar dilation, but it could also be due to other vascular effects related to the activation of endothelial cells in postcapillary venules, possibly via activation of adhering neutrophils. The postcapillary venules are known to respond to inflammatory mediators and cytokines, some of which may be induced by maxadilan itself [43].

The effect of maxadilan lasted longer than that of PACAP-38 and was inhibited by the maxadilan mutant M-65, which had no influence on the PACAP-38 effect. It is possible that the maxadilan peptide is more selective in stimulating PAC-1 receptors, while PACAP-38 may also stimulate VPAC1 and VPAC2 receptors [44]. 
Although PACAP6-38 acts as a PACAP receptor antagonist in most cells/tissues, agonistic functions in other biological systems have also been reported [45]. In our model of skin microcirculation, the PACAP6-38-induced vasodilation differed from that induced by maxadilan or PACAP-38, and, furthermore, counteracted maxadilaninduced vasodilation. Using plasma leakage as determining factor, however, PACAP6-38 induced similar responses, albeit at 60 -fold higher molar concentrations than maxadilan.

It has been observed that PACAP could act as an activator of human neutrophils and monocytes [30, 31], and thus it is possible that the hamster neutrophils may be activated by PACAP-38 or maxadilan, hence releasing granule proteins which eventually cause endothelial cell separation and subsequent long-lasting plasma leakage.

It is well established that a non-inflammatory physiological vasodilator such as acetylcholine may produce increases in blood flow and small vein pressure comparable to that induced by bradykinin and histamine, but without provoking plasma extravasation $[46,47]$. Actually, other types of vasodilators, e.g. $\beta_{2}$-adrenoceptor agonists (e.g. terbutaline and salbutamol) and phosphodiesterase inhibitors (e.g. theophylline, milrinone and rolipram) may counteract histamine- and bradykinininduced plasma leakage $[23,47,48]$. Thus, acetylcholine causes vasodilation without plasma leakage, but histamine and bradykinin cause arteriolar dilation and also act on the postcapillary venular endothelium, hence inducing plasma extravasation. The vasodilation induced by exogenous bradykinin and histamine is of brief duration, and the concomitant increase in plasma leakage is resolved within $30 \mathrm{~min}$, consequently markedly different from effects induced by SGH, maxadilan and PACAP-38. These three components caused a progressive and longlasting vasodilation which peaked after $10-15 \mathrm{~min}$, yet the effect was coupled to an independent increase in plasma leakage. Of note, the extravasation of FITC-dextran was protracted in the SGH and maxadilan groups, but started to decrease 30 min after application of PACAP-38. The long-lasting vasodilation and persistent increase in plasma leakage by maxadilan may be explained by studies investigating maxadilan-induced stimulation of macrophages and dendritic cells resulting in pro-inflammatory cytokine release $[43,49]$.

In 2001, in a study by Morris et al. [41] in mice, half a salivary gland produced effects similar to $3 \mathrm{ng}$ of maxadilan. In our study, SGH- 0.5 produced effects equal to 60 ng of maxadilan $(250 \mu \mathrm{l}$ of a $33-\mathrm{nM}$ solution $=60 \mathrm{ng})$ in terms of vasodilation and plasma leakage. This difference could be due to differences in the content of maxadilan depending on the source L. longipalpis [50].

The possibility that sand fly saliva and maxadilan might activate the kinin system was explored using the bradykinin antagonist HOE-140. Although HOE-140 reduced plasma leakage by $20 \%$, this effect was small compared with the inhibition seen with the maxadilan mutant M-65, which almost completely inhibited the plasma leakage induced either by SGH or maxadilan. Treatment of the HCP with HOE-140 or L-NA prior to maxadilan resulted in no visible changes, suggesting that kinin formation does not play an important role in the microvascular effects induced by maxadilan (data not shown). Given indications that $L$. chagasi promastigotes can induce edema and infect macrophages through the activation of the kinin pathway [34], it will be interesting to determine if the convergence of these responses may have short- or long-lasting effects on the host-parasite relationship. This hypothesis merits analysis in light of recent studies showing that bradykinin, recently characterized as a potent maturation signal for dendritic cells, links innate to type- 1 adaptive immunity in mice infected with Trypanosoma cruzi [51] (for a review, see Scharfstein et al. [52]).

Although limited to studies with SGH and maxadilan so far, our results suggest that sand fly saliva may simultaneously induce vasodilation and plasma leakage, the effects being most probably exerted via the PACAP receptor PAC1. In 1997, Moro and Lerner [15] revealed that maxadilan is a PAC1 receptor agonist without structural similarity to PACAP. Warren et al. $[22,23]$ reported that several vasodilators, e.g. PACAP, enhanced the plasma leakage effect of bradykinin, and in 1997 Cardell et al. [24] showed that PACAP-38 stimulation of rat skin caused plasma leakage and suggested that it could be due to histamine release. More recent studies showed that in the human nose PACAP-38 increased albumin concentration in nasal secretion fluid, which is a sign of plasma leakage [25]. The selective inhibitor used in our study, a 44-amino acid mutant of the 61-amino acid peptide maxadilan, had minor inflammatory effects (plasma leakage) when applied for $10 \mathrm{~min}$ at concentrations 100 times exceeding that of maxadilan. Notably, the M-65 mutant protein completely inhibited both vasodilation and plasma leakage induced by maxadilan. PACAP-38 applied to the cheek pouch in the same way as maxadilan caused vasodilation and plasma leakage corresponding to those of maxadilan, suggesting that part of the immediate inflammatory effect of PACAP-38 could be exerted via $\mathrm{PAC1}$ receptor stimulation. 


\section{Conclusion}

Apart from their predicted vasodilatory effects, SGH, maxadilan and PACAP-38 were able to independently evoke plasma leakage in the cheek pouch. The finding that the M-65 mutant of maxadilan reduced both vasodilation and plasma leakage induced by SGH or maxadilan suggests that their vasoactive and pro-inflammatory effects are at least partially mediated by activation of PAC1 receptors. Vascular permeability increase as well as the well-recognized vasodilation induced by SGH and its component maxadilan might also be an important factor for the development of inflammation at early stages of Leishmania infection. Further studies are necessary to elucidate to what extent the induced plasma leakage is due to consequences of neutrophil activation.

\section{Acknowledgments}

Our study was supported by grants from $\mathrm{CNPq}$ (National Council for Scientific and Technological Development) project no. 410552/2006-2 and FAPERJ (Foundation for Research Support of the Rio de Janeiro State) E-26/100.938/2007.

\section{References}

1 Ribeiro JM: Role of saliva in blood-feeding by arthropods. Annu Rev Entomol 1987;32: 463-478.

2 Gillespie RD, Mbow ML, Titus RG: The immunomodulatory factors of bloodfeeding arthropod saliva. Parasite Immunol 2000; 22:319-331.

3 WHO: Leishmaniasis: background information. www.who.int/leishmaniasis/en. 2008.

-4 Soares RP, Turco SJ: Lutzomyia longipalpis (Diptera: Psychodidae: Phlebotominae): a review. An Acad Bras Cienc 2003;75:301330.

-5 Andrade BB, de Oliveira CI, Brodskyn CI, Barra A, Barral-Netto M: Role of sand fly saliva in human and experimental leishmaniasis: current insights. Scand J Immunol 2007; 66:122-127.

6 Rohousová I, Volf P: Sand fly saliva: effects on host immune response and Leishmania transmission (review). Folia Parasitol(Praha) 2006;53:161-171.

7 Titus RG, Bishop JV, Meija JS: The immunomodulatory factors of arthropod saliva and the potential of these factors to serve as vaccine targets to prevent pathogen transmission. Parasite Immunol 2006;28:131-141.

8 Ghosh KN, Mukhopadhyay J: The effect of anti-sandfly saliva antibodies on Phlebotomus argentipes and Leishmania donovani. Int J Parasitol 1998;28:275-281.

-9 Lima HC, Titus RG: Effects of sand fly vector saliva on development of cutaneous lesions and the immune response to Leishmania braziliensis in $\mathrm{BALB} / \mathrm{c}$ mice. Infect Immun 1996;64:5442-5445.

10 Mbow ML, Bleyenberg JA, Hall LR, Titus RG: Phlebotomus papatasi sand fly salivary gland lysate down-regulates a Th1, but upregulates a Th2, response in mice infected with Leishmania major. J Immunol 1998; 161: 5571-5577.

Salivary Gland Homogenates and Maxadilan Cause Plasma Leakage
1 Norsworthy NB, Sun J, Elnaiem D, Lanzaro G, Soong L: Sand fly saliva enhances Leishmania amazonensis infection by modulating interleukin-10 production. Infect Immun 2004;72:1240-1247.

12 Titus R, Ribeiro J: Salivary gland lysates from the sand fly Lutzomyia longipalpis enhances Leishmania infectivity. Science 1988; 239:1306-1308.

13 Lerner EA, Ribeiro JM, Nelson RJ, Lerner MR: Isolation of maxadilan, a potent vasodilatory peptide from the salivary glands of the sand fly Lutzomyia longipalpis. J Biol Chem 1991;266:11234-11236.

14 Lerner EA, Shoemaker CB: Maxadilan: cloning and functional expression of the gene encoding this potent vasodilator peptide. J Biol Chem 1992;267:1062-1066.

15 Moro O, Lerner EA: Maxadilan, the vasodilator from sand flies, is a specific pituitary adenylate cyclase activating peptide type 1 agonist. J Biol Chem 1997;272:966-970.

16 Lerner EA, Iuga AO, Reddy VB: Maxadilan, a PAC1 receptor agonist from sand flies. Peptides 2007;28:1651-1654.

17 Pereira P, Reddy VB, Kounga K, Bello Y, Lerner E: Maxadilan activates PAC1 receptors expressed in Xenopus laevis melanophores. Pigment Cell Res 2002;15:461-466.

- 18 Miyata A, Arimura A, Dahl RR, Minamino N, Uehara A, Jiang L, Culler MD, Coy DH: Isolation of a novel 38 residue-hypothalamic polypeptide which stimulates adenylate $\mathrm{cy}$ clase in pituitary cells. Biochem Biophys Res Commun 1989;64:567-574.

19 Arimura A: Pituitary adenylate cyclase activating polypeptide (PACAP): discovery and current status of research. Regul Pept 1992; 37:287-303.

20 Arimura A, Shioda S: Pituitary adenylate cyclase activating polypeptide (PACAP) and its receptors: neuroendocrine and endocrine interaction. Front Neuroendocrinol 1995;16: 53-88.
21 Reddy VB, Iuga AO, Kounga K, Lerner EA: Functional analysis of recombinant mutants of maxadilan with a PAC1 receptor-expressing melanophore cell line. J Biol Chem 2006; 24:16197-16201.

22 Warren JB, Larkin SW, Coughlan M, Kajekar R, Williams TJ: Pituitary adenylate cyclase activating polypeptide is a potent vasodilator and oedema potentiator in rabbit skin in vivo. Br J Pharmacol 1992;106:331-334.

23 Warren JB, Wilson AJ, Loi RK, Coughlan ML: Opposing roles of cyclic AMP in the vascular control of edema formation. FASEB J 1993;7:1394-1400.

24 Cardell LO, Stjärne P, Wagstaff SJ, Agusti C, Nadel JA: PACAP-induced plasma extravasation in rat skin. Reg Pept 1997;71:67-71.

25 Kinhult J, Adner M, Uddman R, Cardell LO: Pituitary adenylate cyclase-activating polypeptide, effects in the human nose. Clin Exp Allergy 2003;33:942-949.

26 Valenzuela JG, Garfield M, Rowton ED, Pham VM: Identification of the most abundant secreted proteins from the salivary glands of the sand fly Lutzomyia longipalpis, vector of Leishmania chagasi. J Exp Biol 2004;207:3717-3729.

27 Bozza M, Soares MB, Bozza PT, Satoskar AR, Diacovo TG, Brombacher T, Titus RG, Shoemaker CB, David JR: The PACAP-type 1 receptor agonist maxadilan from sand fly saliva protects mice against lethal endotoxemia by a mechanism partially dependent on IL-10. Eur J Immunol 1998;28:31203127.

28 Soares MB, Titus RG, Shoemaker CB, David JR, Bozza M: The vasoactive peptide maxadilan from sand fly saliva inhibits TNF- $\alpha$ and induces IL- 6 by mouse macrophages through interaction with the pituitary adenylate cyclase-activating polypeptide (PACAP) receptor. J Immunol 1998;160:18111816. 
-29 Teixeira MJ, Teixeira CR, Andrade BB, Barral-Netto M, Aldina Barral A: Chemokines in host-parasite interactions in leishmaniasis. Trends Parasitol 2006;22:32-40.

-30 Harfi I, D’Hondt S, Corazza F, Sariban E: Regulation of human polymorphonuclear leukocytes functions by the neuropeptide pituitary adenylate cyclase-activating polypeptide after activation of MAPKs. J Immunol 2004;173:4154-4163.

-31 El Zein N, Badran BM, Sariban E: The neuropeptide pituitary adenylate cyclase-activating protein stimulates human monocytes by transactivation of the Trk/NGF pathway. Cell Signal 2007;19:152-162.

-32 Svensjö E: Bradykinin and prostaglandin E1, E2 and F2-alpha-induced macromolecular leakage in the hamster cheek pouch. Prostaglandins Med 1978;1:397-410.

33 Svensjö E: The hamster cheek pouch as a model in microcirculation research. Eur Respir J Suppl 1990;3:595s-601s.

>34 Svensjö E, Batista PR, Brodskyn CI, Silva R, Lima APC, Schmitz V, Saraiva EM, Pesquero JB, Mori MAS, Müller-Esterl W, Scharfstein $\mathrm{J}$ : Interplay between parasite cysteine proteases and the host kinin system modulates microvascular leakage and macrophage infection by promastigotes of the Leishmania donovani complex. Microbes Infect 2006;8: 206-220.

35 Mayhan WG, Joyner WL: The effect of altering the external calcium concentration and a calcium channel blocker, verapamil, on microvascular leaky sites and dextran clearance in the hamster cheek pouch. Microvasc Res 1984;28:159-179.

-36 Persson NH, Erlansson M, Svensjö E, Takolander R, Bergqvist D: The hamster cheek pouch - an experimental model to study postischemic macromolecular permeability. Int J Microcirc Clin Exp 1985;4:257-263.

>37 Gawlowski DM, Duran WN: Dose-related effects of adenosine and bradykinin on microvascular permselectivity to macromolecules in the hamster cheek pouch. Circ Res 1986;58:348-355.
38 Erlansson M, Svensjö E, Bergqvist D: Leukotriene $\mathrm{B}_{4}$-induced permeability increase in postcapillary venules and its inhibition by three different antiiflammatory drugs. Inflammation 1989;13:693-705.

39 Erlansson M, Bergqvist D, Persson NH, Svensjö E: Modification of postischemic increase of microvascular permeability in the hamster by iloprost. Prostaglandins 1991;4: 157-168.

40 Armenante PM, Kim D, Duran WN: Experimental determination of linear correlation between in vivo TV intensity and vascular and tissue FITC-DX concentrations. Microvasc Res 1991;42:198-208.

41 Morris RV, Shoemaker CB, David JR, Lanzaro GC, Titus RG: Sandfly maxadilan exacerbates infection with Leishmania major and vaccinating against it protects against $L$. major infection. J Immunol 2001;167:52265230.

42 Svensjö E: The hamster cheek pouch as a research model in inflammation; in Shepro D (ed): Microvascular Research - Biology and Pathology. Amsterdam, Elsevier, 2006, pp 195-207.

43 Brodie TM, Smith MC, Morris RV, Titus RG: Immunomodulatory effects of the Lutzomyia longipalpis salivary gland protein maxadilan on mouse macrophages. Infect Immun 2007;75:2359-2365.

44 Winzell MS, Ahrén B: Role of VIP and PACAP in islet function. Peptides 2007;28: 1805-1813.

45 Reglodi D, Borzsei R, Bagoly T, Boronkai A, Racz B, Tamas A, Kiss P, Horvath G, Brubel R, Nemeth J, Toth G, Helyes Z: Agonistic behavior of PACAP6-38 on sensory nerve terminals and cytotrophoblast cells. J Mol Neurosci 2008;36:270-278.
46 Grega GJ, Kline RI, Dobbins DE, Haddy FJ: Mechanisms of edema formation by histamine administered locally into canine forelimbs. Am J Physiol 1972;223:1165-1171.

-47 Svensjö E, Arfors KE, Raymond RM, Grega GJ: Morphological and physiological correlation of bradykinin-induced macromolecular efflux. Am J Physiol 1979;236:H600H606.

48 Svensjö E, Andersson KE, Bouskela E, Cyrino FZ, Lindgren S: Effects of two vasodilatory phosphodiesterase inhibitors on bradykinin-induced permeability increase in the hamster cheek pouch. Agents Actions 1993; 39:35-41.

49 Wheat WH, Pauken KE, Morris RV, Titus RG: Lutzomyia longipalpis salivary peptide maxadilan alters murine dendritic cell expression of CD80/86, CCR7, and cytokine secretion and reprograms dendritic cell-mediated cytokine release from cultures containing allogeneic T cells. J Immunol 2008; 180:8286-8298

50 Warburg A, Saraiva E, Lanzaro GC, Titus RG, Neva F: Saliva of Lutzomyia longipalpis sibling species differs in its composition and capacity to enhance leishmaniasis. Philos Trans R Soc Lond B Biol Sci 1994;345:223230.

51 Monteiro AC, Schmitz V, Svensjö E, Gazzinelli RT, Almeida IC, Todorov A, Barros de Arruda L, Torrecilhas ACT, Pesquero JB, Morrot A, Bouskela E, Bonomo A, Lima APC, Müller-Esterl W, Scharfstein J: Cooperative activation of TLR 2 and bradykinin $\mathrm{B}_{2}$ receptors is required for induction of type-1 immunity in a mouse model of subcutaneous infection by Trypanosoma cruzi. J Immunol 2006;177:6325-6335.

-52 Scharfstein J, Schmitz V, Svensjö E, Granato A, Monteiro AC: Kininogens coordinate adaptive immunity through the proteolytic release of bradykinin, an endogenous danger signal driving dendritic cell maturation. Scand J Immunol 2007;66:128-136. 